\title{
INVESTIGATION OF EXTERNEL BONDED PATCH REPAIR OF LAMINATED COMPOSITE MATERIALS EXPERIMENTALY
}

\author{
Şükrü ÇETINKAYA ${ }^{1}$, Haşim PIHTILI ${ }^{2}$, Hayri YILDIRIM ${ }^{3 *}$ \\ ${ }^{1}$ Mechanical Engineering Depertmant / Dicle University, Turkey \\ ${ }^{2}$ Mechanical Engineering Depertmant / Firat University, Turkey \\ ${ }^{3}$ Diyarbakır Technical Science Vocational School / Dicle University \\ * Corresponding author; E-mail: hyildirim@dicle.edu.tr \\ Received: 17 October 2018; Accepted: 18 December 2018
}

\begin{abstract}
For this study, woven glass and carbon fibres reinforced composite materials were produced. Composite materials have been produced with eight laminates. For experimental study, specimens with $10 \mathrm{~mm}$ internal hole were prepared. Then, these specimens were repaired by using adhesive and composite patches with different repair parameters. Two different bonding patch type were used for external bonding patch repair of the specimens. These were wet lay out patches and prepreg patches. Test specimens were prepared in necessary curing temperatures and laboratory conditions. By performing the unidirectional tensile test to these specimens, the ultimate failure loads of these repaired specimens were indicated. By comparing these ultimate failure loads of repaired specimens that prepared with various parameters, the effects of several repair parameters on the ultimate failure strength are investigated. These repair parameters are patch bonding area (D/W ratio), bonding length, adhesive thickness and patch thickness.
\end{abstract}

Key words: Laminate Composite Materials, bonded repair, patch, adhesive, failure strength

\section{Introduction}

With technological improvements, applications of composite materials have been increased both commercial and military aircraft structures applications in recent years. For such applications, composite materials have excellent properties. Due to high cost of these materials, maintenance of them, have been 
important. In industry, spare parts repair of these composite materials, have been preferred than replacement of spare parts. Sometimes, replacements of the damaged spare parts are costly and unnecessary. Nowadays, more structures that prepared by composite materials with a few defects or local damages can be repaired successfully.

In industry, various repair techniques have been successfully applied. Among them, adhesively bonded structural repair has gained more favour than mechanically fastened structural repair for the reason that fibber reinforced composites are essentially bonded in nature. Therefore, in recent years, considerable experimental and numerical studies have been conducted to investigate the influence of different repair parameters on the stress distributions, ultimate strength and stress intensity factor of the bonded repaired structures [1]. A number of authors [1-9,11,16] have studied the analysis of failure mechanism of the bonded patch repair in laminated composite materials. Wisnom M.R. [10] has reviewed the size effects in the testing of fibre-composite materials. Predictive fracture model for composite bonded joints has been proposed by Goyal V.K. and et al. [12]. Principles and practices of adhesive bonded structural joints and repairs have studied by Davis M. [13]. Little research has been carried out to analyse the ultimate failure load of repaired structures with various repair parameters.

In aircraft applications, less weight is the important criteria for the maintenance of the parts. For such repair applications in laminated composite materials, external bonded patch repair technique has been more preferable than using mechanical fastened repair. Because, using mechanical fasteners increase the weight and the stress concentration factor of the repaired structures. Also, in external patch bonding repair, the optimum quantity of repair materials must be used in order to protect weight increment of the repaired structure. These main repair materials are adhesives and composite patches. The adhesives and patches should have been used in minimum quantity in repairs without degrease the load carrying capacity of the structures. Also, in adhesively bonded repairs, the stresses that occur in bonded joints are more uniform than that of pinned joints. These stress representations for various connections are illustrated in Fig. 1.
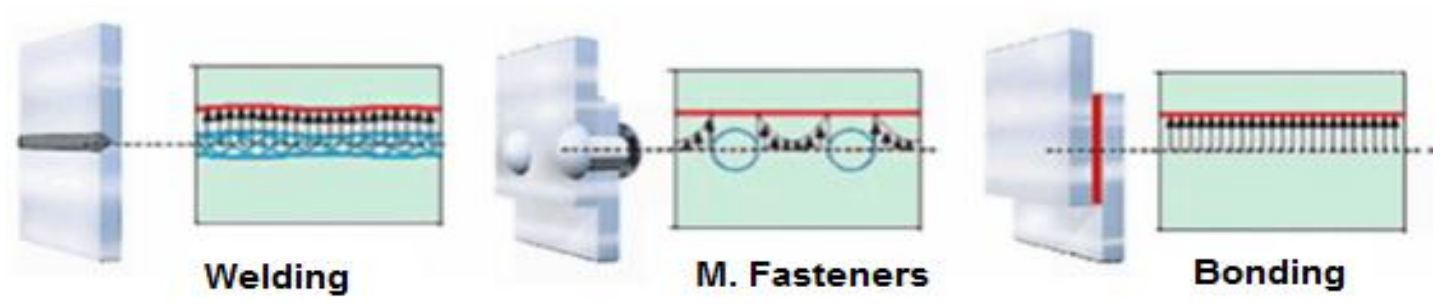

Figure 1. Stress concentration effects for various joints [15].

In this study, various experimental specimens have produced with different repair parameters. Then, by performing unidirectional tensile testing to these prepared specimens, the ultimate failure loads of them 
were indicated. By analysing these failure loads of the specimens, the effects of repair parameters have been specified.

\section{Experimental}

The current work investigated the performance of the external bonded patch repairs under tensile loading by indicating the ultimate failure loads of repaired laminated composite structures. For this study, eight plies laminated woven glass and carbon fibres reinforced parent plates were used. By using these parent plates, experimental specimens were prepared. $10 \mathrm{~mm}$ holes were drilled in the centre of the parent plates to simulate the damages in the structures. Then, these damaged specimens were repaired by using adhesive and composite patches with different parameters in laboratory conditions. Two different bonding patch type were used for external bonding patch repair of the specimens. These were wet lay out patches and prepreg patches. Test specimens were prepared in necessary curing temperatures and laboratory conditions. By performing the unidirectional tensile test to these specimens, the ultimate failure loads of these repaired specimens were indicated. The repaired experimental specimens were shown in Fig. 2. The materials that used for parent plate specimens, adhesives and patches in repair were listed in Table1. During the tests, specimens were subjected to longitudinal tensile loads on tensile testing machine in order to indicate the failure loads of repaired structures.

Table 1. Materials that were used in repair of laminated composite materials

\begin{tabular}{|c|c|c|c|}
\hline Bonding type & Parent Materials & Adhesive & Patch Material \\
\hline \multirow{2}{*}{ W.L. } & Woven carbon fibres & Hysol EA9396 & 0020989 \\
\cline { 2 - 4 } & Woven glass fibres & Hysol EA9396 & $0021438-09$ \\
\hline \multirow{2}{*}{ Prepreg } & Woven carbon fibres & C992275 ADH FILM & C992268-14 \\
\cline { 2 - 4 } & Woven glass fibres & C991957-37 ADH & C992270 \\
& & FILM & \\
\hline
\end{tabular}

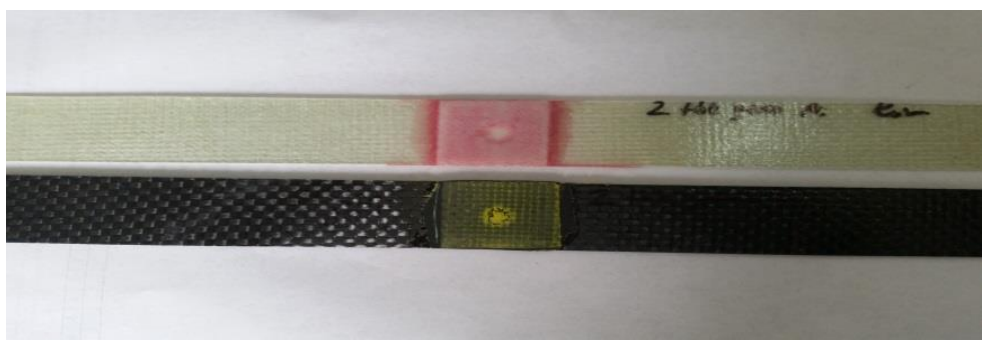

Figure 2. Presentation of repaired experimental specimens

\section{Results and discussion}

\subsection{Effect of patch thickness}

The effect of the patch thickness to the ultimate failure loads of repaired structure was indicated in Fig. 3. The ultimate failure loads of the structures repaired with prepreg bonding technique were increased by increasing the patch thickness (increase the ply number). But, for the structure that repaired with W.L. bonding technique, the failure loads have increased gradually to the patch thickness of the 3 plies values and after that, the peeling effect has occurred in repaired structure than, the failure load decrease dramatically. Increase the bonded patch thickness after a certain value (3 plies) in repair of the laminate composite materials does not improve the ultimate failure load. Increase the patch thickness further in 
repair of air craft structures may cause the weight stability effect. This is the main drawback in repairs of such applications.

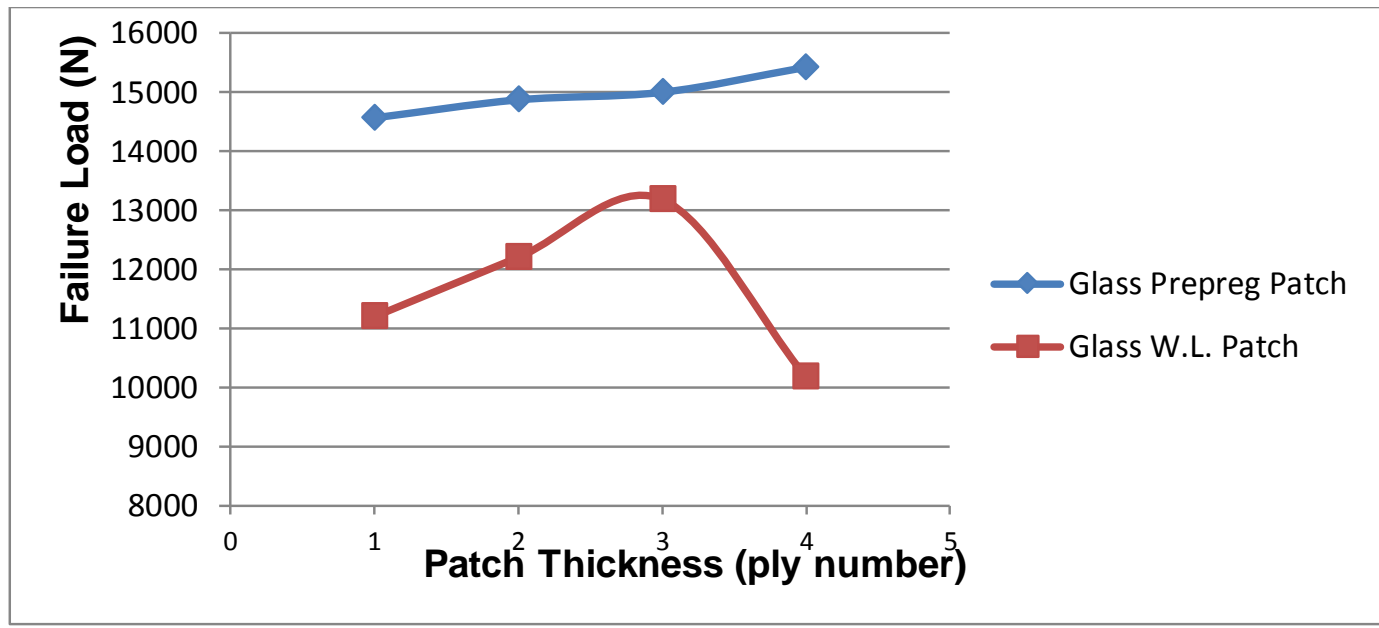

Figure 3. Effect of patch thickness to the failure load of repaired structures with glass prepreg

\subsection{Effect of bonding length} and wet layout patches.

In external bonded patch repairs, if the patch overlap length or bond length too short, the entire adhesive layer is under high shear stress. In the case of longer bond length, most of the load is carried at the ends of the bonded overlap which is the reason for why too large patches fails to enhance the expected ultimate strength [14]. Effect of bonding length of the patch to failure loads in repaired structures has presented in Fig. 4. The failure loads of structures repaired with glass prepreg patches bonding were increased gradually by increasing the bonding length in repair. In that repair with glass W.L. patch bonding; the failure loads were increased to the bonding length of $40 \mathrm{~mm}$ gradually, than decrease dramatically to the $5850 \mathrm{~N}$ value due to peeling effect that presented in W.L. applications. In bonded patch repair, for both W.L. and prepreg patches, $40 \mathrm{~mm}$ value of bonding length, was seen as the optimum value.

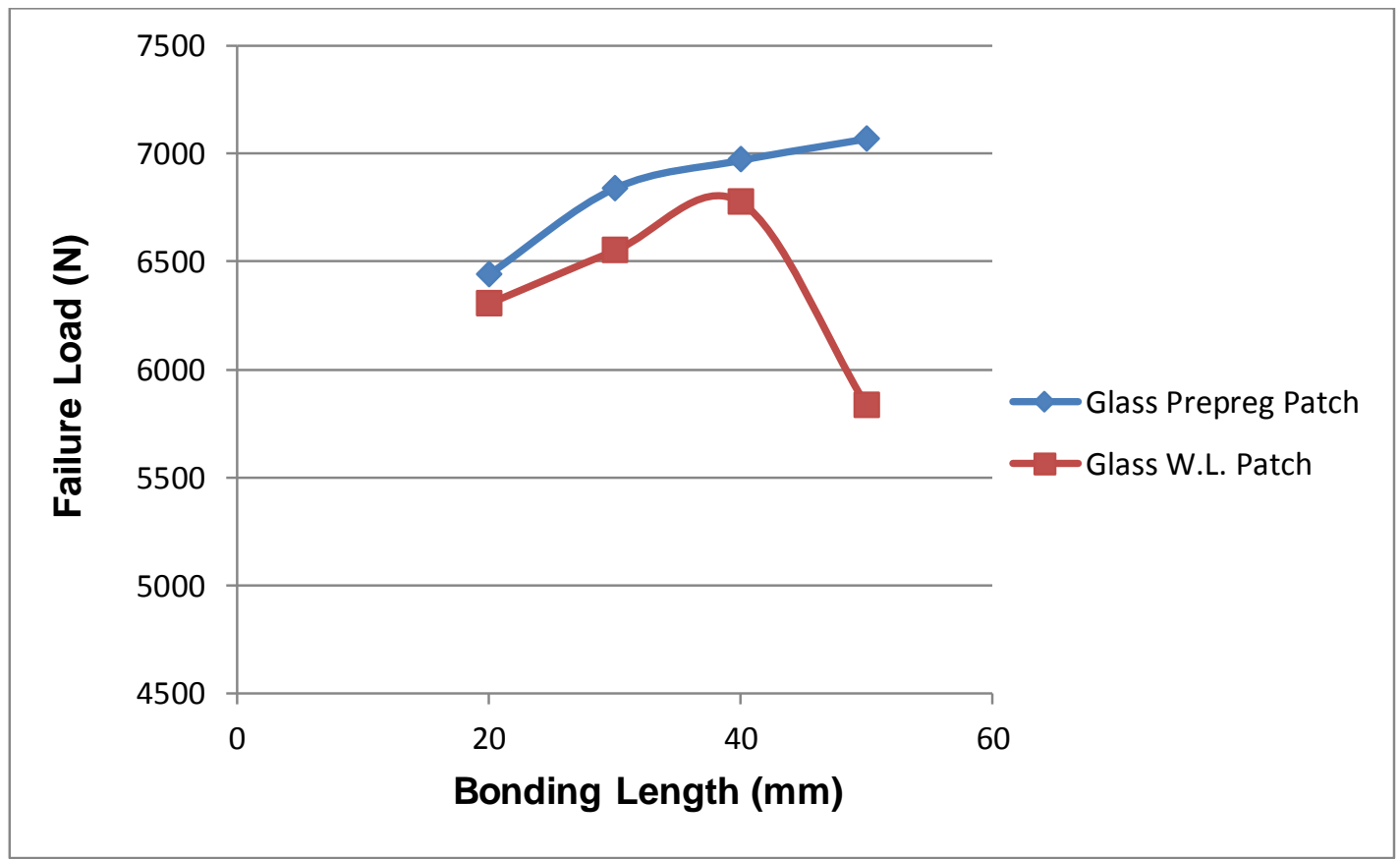

Figure 4. Presentation of the effect of bonding length to the failure load of $W / D=2$ glass repaired structures with glass prepreg and wet layout patches. 


\subsection{Effect of bonding area (W/D ratio)}

Effect of bonding area (W/D ratio) to the ultimate failure loads was presented in Fig. 5. By changing the W/D ratio from 2 to 4 in repair with carbon fibres prepreg, the failure loads of the repaired laminated plates have been changed from $20000 \mathrm{~N}$ to $50000 \mathrm{~N}$ value. In repair of woven laminated composite materials, the change of W/D ratio has major effect in ultimate failure loads of repaired parent plate materials. Increase the W/D ratio further in repair of structures may cause the weight stability effect. For this reason, in repair of laminated composite materials the W/D ratio should be in optimum value.

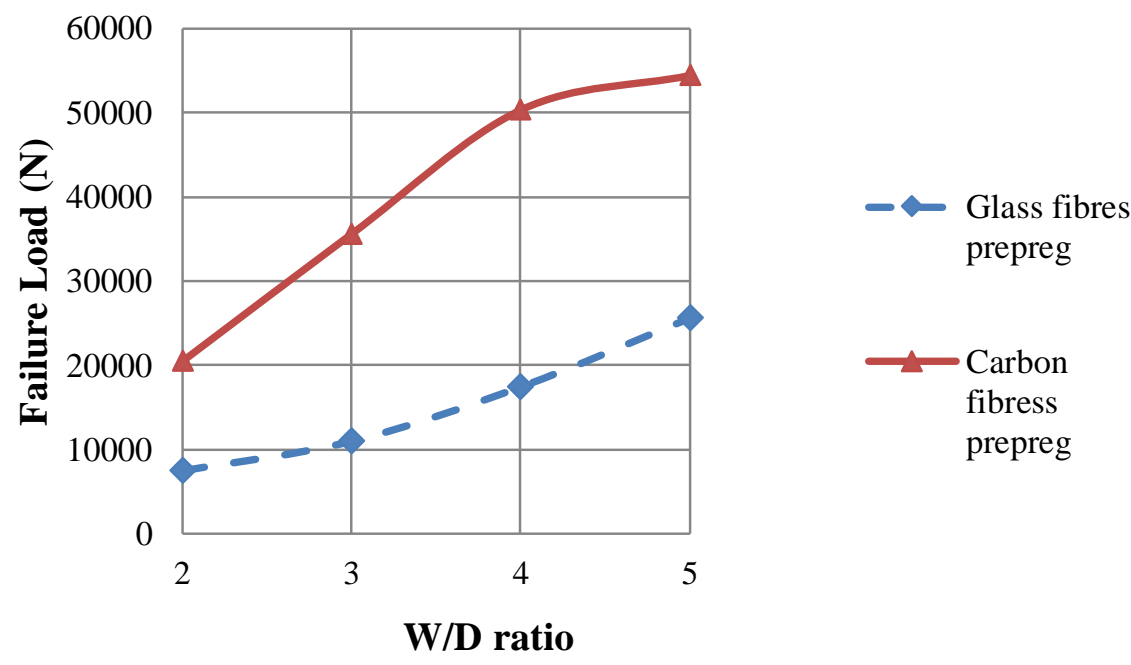
Figure 5. Presentation of the effect of W/D ratio to the failure load glass and carbon fibres
reinforced plates repaired structures with glass and carbon prepreg patches.

\subsection{Effect of adhesive thickness}

The adhesives, which bond the patches and parent plates together, are always regarded as the weakest chain in the bonded repair, and play an essential role. Therefore, careful selection of its parameters is very important [1]. In this study, effects of adhesive thickness were studied with the W/D=3 carbon parents laminated composite specimens that repaired with carbon prepreg patches by using various adhesive film thicknesses. The effect of adhesive thickness in repair of laminated composite materials with external bonded patch to the ultimate failure loads was illustrated in Fig. 6. For each adhesive film ply thickness was taken as $0.2 \mathrm{~mm}$. The maximum ultimate failure load $(40750 \mathrm{~N})$ was obtained with 3 plies adhesive thickness $(0.6 \mathrm{~mm})$ in repair of woven carbon fibres laminated parent plates with external carbon prepreg bonded patches.

The adhesive material which bonds the patch to the parent laminate is considered as the most important factor in the patch bonding repair design. If the adhesive layer is too thin, it will be stiff and brittle which can result to a shear failure initiation in high stress regions near the patch and hole edges, causing the damage propagates across the entire overlap region. However, if the adhesive layer is too thick, it will be too plastic and under loading it is expected to deform quickly which weakens the effectiveness of load transfer between the parent laminate and patches [14]. 


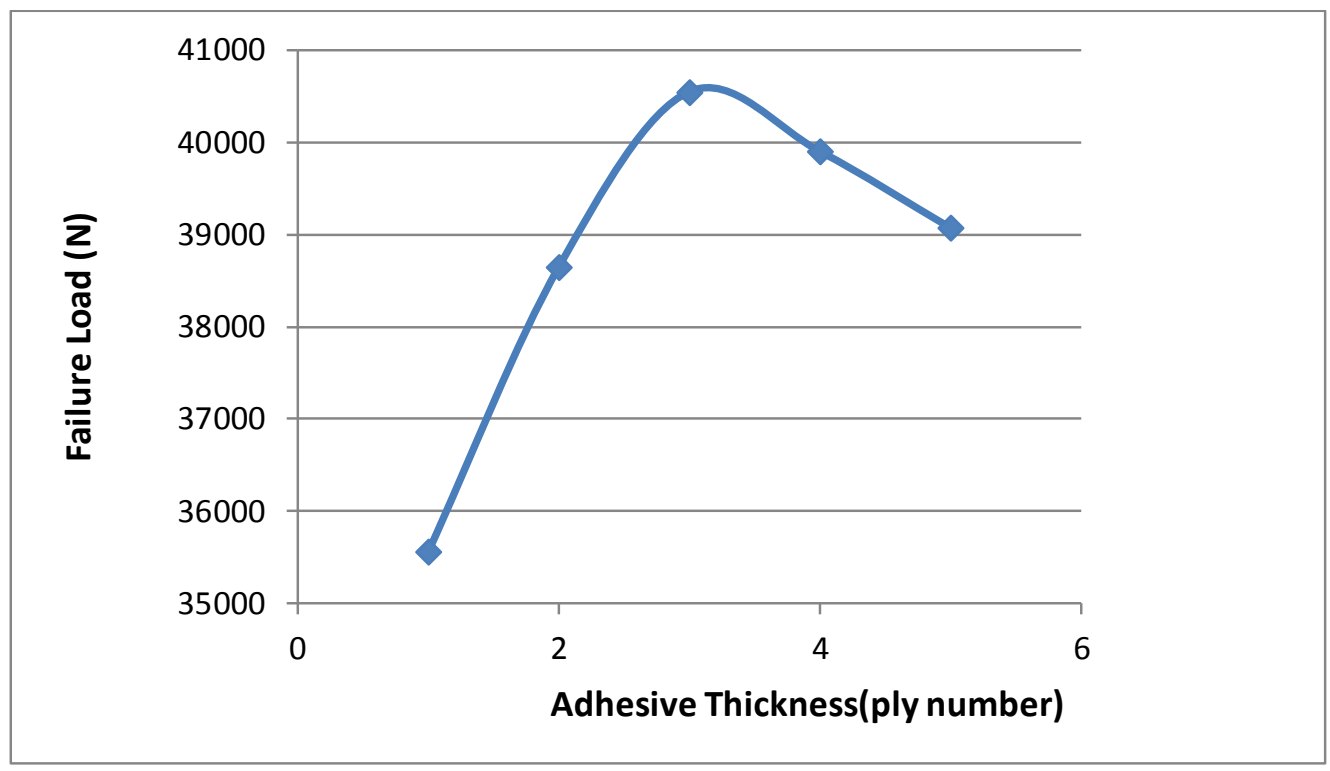

Figure 6. Presentation of the effect of adhesive thickness to the failure load of W/D=3 carbon parent laminated composite that repaired with carbon prepreg patches.

\section{Conclusions}

In the present study, experimental study is carried out to investigate the effect of different repair parameters on the ultimate failure load of adhesively bonded repaired structures, and the following conclusions can be drawn from this study.

1. The ultimate failure loads of the structures repaired with prepreg patches bonding technique were increased by increasing the patch thickness. But, for the structure that repaired with W.L. bonding technique, the failure loads have increased gradually to the patch thickness of the 3 plies values and after that, the peeling effect has occurred easily and this decrease the failure loads of repaired structures.

2. In external bonded patch repair, for both W.L. and prepreg patches, $40 \mathrm{~mm}$ value of bonding length, was seen as the optimum value for obtaining maximum ultimate failure load of repaired specimens.

3. Ultimate failure loads of repaired structures can be increased by choosing the optimum repair parameters, such as patch dimensions, adhesive thickness, bonded area and bonding length.

4. In repair of air craft structures, due to weight stability, optimum quantity of repair materials should be used.

\section{References}

[1] Liu X., Wang G. (2007). Progressive failure analysis of bonded composite repairs. Composite Structures, 81, 331-340.

[2] Papanikos P., Tserpes K.I., Pantelakis Sp.(2007). Initiation and progression of composite patch debonding in adhesively repaired cracked metallic sheets. Composite Structures, 81, 303-311.

[3] Xiaoquan C.,Baig Y., Renwei H., Yujian G., Jikui Z., (2013). Study of tensile failure mechanisms in scarf repaired CFRP laminates. International Journal of Adhesion \& Adhesives, $41,177-185$. 
[4] Breitzman T.D., Larve E.V., Cook B.M., Schoeppner G.A., Lipton R.P. (2009), Optimization of a composite scarf repair patch under tensile loading. Composites: Part A, 40, 1921-1930.

[5] Tse P.C., Lau K.J., Wong W.H. (2002), Stress and failure analysis of woven composite plates with adhesive patch-reinforced circular hole. Composites: Part B, 33, 57-65.

[6] Jones R., Chiu W.K. and Smith R., (1995), Airworthiness of Composite Repairs: Failure Mechanisms. Engineering Failure Analysis, 2, 117-128.

[7] Cheng P., Gong X. J. , Hearn D., Aivazzadeh S., (2011), Tensile behaviour of patch-repared CFRP laminates. Composite Structures, 93, 582-589.

[8] Her S. C. (1999), Stress analysis of adhesively-bonded lap joints. Composite Structures, 47, 673-678.

[9] Campilho R.D.S.G., Moura M.F.S.F., Domingues J.J.M.S., (2009), Numerical prediction on the tensile residual strength of repaired CFRP under different geometric changes. International Journal of Adhesion \& Adhesives, 29, 195-205.

[10] Wisnom M. R., (1999), Size effects in the testing of fibre-composite materials. Composites Science and Technology, 59, 1937-1957.

[11] Madani K., Touzain S., Feaugas X., Cohendouz S., Ratwani M., (2010), Experimental and numerical study of repair techniques for panels with geometrical discontinuities. Computational Materials Science, 48, 83-93.

[12] Goyal V.K., Johnson E.R., Goyal V.K., (2008), Predictive strength-fracture model for composite bonded joints. Composite Structures, 82, 434-446.

[13] Davis M., Bond D., (1999), Principles and practices of adhesive bonded structural joints and repairs. International Journal of Adhesion \& Adhesives, 19, 91-105.

[14] Caminero M.A., Pavlopoulou S., Lopez-Pedrosa M., Nicolaisson B.G., Pinna C., Soutis C., (2013), Analysis of adhesively bonded repairs in composites: Damage detection and prognosis. Composite Structures, 95, 500-517.

[15] Loctite Worlwide Design Handbook, (1988).

[16] Turan K., Kaman M.O.,(2016), Experimental Failure Analysis of Wet-Patch-Repaired U Notched Composite Plates. European Journal of Technic, 6, 91-98. 